\title{
Astrocytoma simultaneously present with Meningioma-a report of two cases and review of the literature
}

\author{
Aihemaiti Hasimu, Qiang Fu, Qingjiu Zhou, Shaoshan Li, Xiaofeng Zhu, Chen Liu, Dangmuren Jiafu Geng \\ and Bo Liu*
}

\begin{abstract}
Background: This research paper will discuss the surgical management and possible mechanisms, as well as enlighten other features which can explain meningioma and astrocytoma simultaneously occurrences including statistical coincidence, the role of common carcinogens, autocrine growth factors and their pathogenic correlations.

Case presentation: We describe two patients with simultaneous presentation of meningioma with astrocytoma. A correct preoperative radiological diagnosis was made in both patients and their tumors were completely removed microscopically. Pathological examinations confirmed that one among them was meningioma and the other an anaplastic astrocytoma. We reviewed the studies carried out regarding meningioma associated with astrocytoma in China as well as in other countries.

Conclusion: In the absence of phacomatosis or prior radiation therapy, the reason for the simultaneous occurrence of astrocytoma with meningioma is not clear, and these tumors could be merely a statistical coincidence. Careful preoperative radiological evaluation and surgical management is of great importance in these patients.
\end{abstract}

Keywords: Astrocytoma, Meningioma, Simultaneous tumors, Surgical management

\section{Background}

Meningioma and astrocytoma are two common primary brain tumors, which commonly occur as solitary lesions. They have a nearly contrary clinical outcome because of their distinctive biological behaviors. The simultaneous occurrence of meningioma and gliotic tumors or even collision tumors are mainly observed in some phacomatosis such as von Recklinghausen neurofibromatosis, and in several other genetic syndromes such as Turcot's and Sipple's syndrome, and also after cranial radiotherapy $[1,2]$. In this article, we report two cases with simultaneous meningioma and astrocytoma occurrence in the same patients without radiotherapy, phacomatosis, or any genetic disorders. The aim of this study is to define surgical management and the etiopathogenic correlations of meningioma with astrocytoma.

\footnotetext{
* Correspondence: boliu133@hotmail.com

Department of Neurosurgery, First Affiliated Hospital of Xinjiang Medical University, 137 Liyushan Road, Xinshi District, Urumqi, Xinjiang 830054, PR of China
}

(c) 2016 Hasimu et al. Open Access This article is distributed under the terms of the Creative Commons Attribution 4.0 International License (http://creativecommons.org/licenses/by/4.0/), which permits unrestricted use, distribution, and reproduction in any medium, provided you give appropriate credit to the original author(s) and the source, provide a link to the Creative Commons license, and indicate if changes were made. The Creative Commons Public Domain Dedication waiver (http://creativecommons.org/publicdomain/zero/1.0/) applies to the data made available in this article, unless otherwise stated.

\section{Case 1}

The 48-year-old woman was presented with weakness of the left upper limb that has developed over six months. This patient had a generalized seizure, a sudden nausea and vomiting four hours before admission. The neurological examination revealed 4/5 left hemiparesis with out any other abnormality. The patient's blood type was $\mathrm{AB}$ positive and the preoperative Karnofsky Performance Score (KPS) was 80. The patient's family history was unremarkable and there were no cutaneous markers in her skin. Cranial Magnetic Resonance Imaging (MRI) revealed a right parietal lobe meningioma. In the right temporal lobe, a low-grade glioma with large edema was found (Fig. 1).

Under general anesthesia, right parietal craniotomy was performed. The parietal lobe meningioma was completely resected microscopically. One day after surgery, the 
Table 1 Clinical data of two reported cases

\begin{tabular}{lll}
\hline & Patient 1 & Patient 2 \\
\hline Age & 48 & 66 \\
Cender & female & male \\
Spatial relationship of two tumors & generalized epileptic seizure & dysphasia \\
Radiological diagnosis & same hemisphere & different hemisphere \\
Treatment & MRI & CT,MRI \\
WHO grading of Meningioma type & two-stage removal irradiation, chemotherapy & one-sage removalirradiation, chemotherapy \\
WHO grading Astrocytoma type & WHO I, transitional & WHO I, psammomatous \\
Outcome(survival after first surgery, months) & WHO III, anaplastic & WHO III, anaplastic \\
\hline
\end{tabular}

patient presented drowsiness and her pupils were seen to be bilaterally fixed at $3.5 \mathrm{~mm}$ with less reaction to light. She was discharged with $0 / 5$ full muscle strength in the left extremities. The non-contrast Computed Tomography (CT) showed intratumoral hemorrhage localized on the right temporal region and midline shifting to the left side (Fig. 2). Under general anesthesia, the patient underwent gross resection of the right temporal tumor at the second stage. An intraoperative frozen section examination confirmed the pathological diagnosis as malignant glioma.

All tissue samples for pathological study were fixed in $10 \%$ buffered formalin. Microscopic sections generated from routinely processed paraffin blocks were stained with Hematoxylin and Eosin (H\&E). Immunohistochemistry was performed with the following panel of antibodies: Epithelial Membrane Antigen (EMA), Glial Fibrillary Acidic Protein (GFAP), CD34, Vimentin (Vim), Ki-67, CD57, CK, S-100 protein, and Olig-2.

The histopathological report confirmed the presence of a transitional meningioma with fibroblastic tissue and whorls of meningothelial cells with few psammoma bodies. The right temporal lesion was hypercellular parenchyma consisting of pleomorphic astrocytic cells with thrombosis. There was no evidence of vascular proliferation or necrosis (Fig. 3). Immunohistochemistry results and major biomarkers are summarized in Table 2.
One month later, the patient's postoperative KPS was 70. The patient experienced an increase in her hemiparesis in the postoperative period and underwent radiation therapy (60 Gy) in conjunction with daily temozolomide $(75 \mathrm{mg} /$ $\mathrm{m}^{2}$ /day) for 42 days followed by a 4-month course of temozolomide ( $200 \mathrm{mg} / \mathrm{m}^{2}$ for 5 days per 28 -day cycle). She tolerated the adjuvant therapy well. However, the patient was lost to follow-up five months after the first surgery.

\section{Case 2}

A 65-year-old man had presented with speech difficulty and walking instability about one day before admission. The patient was fully oriented and without any neurological deficits. The patient had no history of a neurocutaneous disorder, previous head trauma, surgery or irradiation of the head. The patient's family history concerning any precedence in neurofibromatosis was reported as negative. The patient's blood type was A positive and preoperative KPS was 90. Pre-operative non- contrast CT scan showed the right frontal falx meningioma with calcification and a left frontal mass lesion. MRI disclosed a right frontal falx meningioma and the left frontal, corpus callosum highgrade glioma (Fig. 4).

Under general anesthesia, a bicoronal incision with right frontal and left frontal craniotomy was performed. Meningioma and astrocytoma were totally removed. The left frontal, corpus callosum surgical specimen consisted
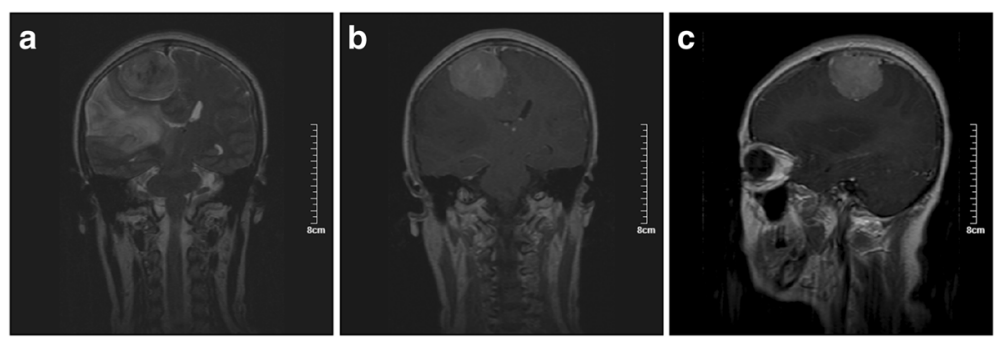

Fig. 1 Pre-operative MRI of patient one. Marked large edema is appreciated in the $T_{2}$-weighted modus (a). $T_{1}$-weighted images with gadolinium contrast. A coronary (b) and sagittal (c) views showed the right parietal lobe meningioma and the right temporal lobe low-grade glioma 

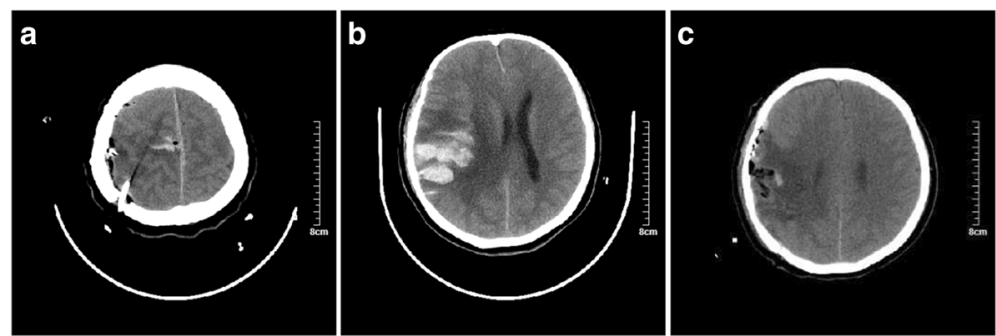

Fig. 2 Post-operative CT of patient one. One day after first surgery non-contrast computed tomographic (CT) axial view showing intratumoral hemorrhage localized on the right temporal region ( $\mathbf{a}$ and $\mathbf{b}$ ). Six hours after second stage surgery CT showing right temporal lobe mass lesion was removed $(\mathbf{c})$

of several white to grayish, rubbery in consistency, soft tissue, totaling about $4.5 \mathrm{~cm} \times 4.5 \mathrm{~cm} \times 1.6 \mathrm{~cm}$. Whereas, resection fragments derived from the right frontal tumor were grayish and added up to $4 \mathrm{~cm} \times 3 \mathrm{~cm} \times 1.5 \mathrm{~cm}$ (Fig. 5). A psammomatous meningioma WHOIand anaplastic astrocytoma WHO III were diagnosed by hematoxylin and eosin staining and immunohistological examination (Fig. 6). Immunohistochemistry results and major biomarkers are summarized in Table 2. Post-operative CT and MRI demonstrated tumor residual cavity (Fig. 7).

The patient's postoperative KPS score was 90. During the following two months, the patient received external beam radiotherapy with 59.4 Gy and two complete cycle of temozolomide. Before starting the third cycle, routine MRI revealed tumor recurrence four months after first surgery. The patient refused further surgical intervention and received gamma-knife surgery and three further cycles of temozolomide at another hospital. The patient did not recover from his neurological symptoms and died 8 months after the first intervention.

\section{Discussion}

Primary central nervous system neoplasms may be multifocal including a small percentage of gliomas in the setting of von Hippel-Lindau disease, and meningioma in the setting of neurofibromatosis [3, 4]. The simultaneous or even collision occurrence of primary intracranial tumors

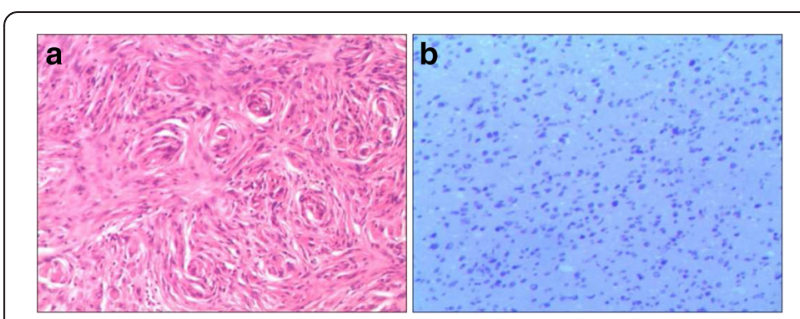

Fig. 3 Hematoxylin and eosin (H\&E) staining showing the results of pathological examinations of patient one ( $\mathbf{a}$ and $\mathbf{b}$ ). Photomicrograph a showing a tumor composed of meningothelial cells in whorls. Photomicrograph $\mathbf{b}$ showing malignant astrocytoma with hypercellularity and nuclear plemorphism (H\&E × 400, medium power) without neurofibromatosis II and cranial radiotherapy is reported infrequently. Meningioma has an increased probability of developing another primary or secondary brain tumor. Meningioma is the most common central nervous system tumor to host a metastatic cancer $[5,6]$. Among them, the simultaneous or coexistence of an intracranial meningioma and an astrocytoma seems to be one of the most commonly encountered type of tumor [7-9].

We have reviewed the literature and found cases of concurrent astrocytoma and meningioma similar to our cases, excluding brain injury, phacomatosis or genetic disorders and cranial radiotherapy (Table 3).

The etiology of this phenomenon remains unknown. Multiple theories have been postulated in the literatures for the simultaneous or collision occurrence of these tumors. However, the exact mechanism underlying this observation is yet to be defined. Exposure to biochemical substances, genetic factors, prior trauma or surgery and immunological mechanisms may be the causative or contributory factors in the development of these tumors $[3,10]$.

Some studies believe that such cases are largely incidental in their nature [11]. Meningioma is relatively a common tumor of the CNS constituting about $18 \%$ of brain tumors. Similarly, glioma accounts for 40-50 \% of primary brain tumors [12]. The incidence of multiple intracranial tumors of different histology is 10-15 cases per 100,000 who develop primary brain tumors [13], and from a statistical perspective chances of recurrence in the same patient is possible. Meningioma and glioma, whether they exist together or separate are relatively common forms of neoplasms involving the brain, and their concurrence in many cases maybe coincidental. Many genetic factors may also be involved and a genetic study in such cases with this condition is advisable [14].

Another theory suggests that, astrocytoma may develop due to neoplastic transformation of the reactive glial cells surrounding a meningioma $[1,15,16]$. Juxtaposition of these diverse germinal origin tumors in the same patient suggests that one tumor may act as an irritating agent for the local proliferation and growth of the other. Growth of 
Table 2 Immunohistochemical results and major biomarkers of the two reported cases

\begin{tabular}{|c|c|c|c|c|c|c|c|c|c|c|}
\hline & & EMA & GFAP & CD34 & Vim & Ki67\% & CD57 & CK & S-100 & Olig-2 \\
\hline \multirow[t]{2}{*}{ Case 1} & meningioma & + & - & + & - & 1 & - & - & - & \\
\hline & astrocytoma & - & + & + & + & 10 & & & & + \\
\hline \multirow[t]{2}{*}{ Case 2} & meningioma & + & - & & + & 1 & & & - & \\
\hline & astrocytoma & + & + & & & & + & - & + & + \\
\hline
\end{tabular}

-, none to weak; +, intermediate; ++, strong; \pm , occasional

human tumors cell in these cases follows autocrinous mechanism. Among RTK signaling molecules, it has been suggested that expression of platelet-derived growth factor receptor (PDGFR) is involved in the tumorigenesis and malignant progression of meningioma [17], and the most suspected substance is platelet-derived growth factor (PDGF) [16]. Three subunits of PDGF, the PDGF-AA, PDGF-BB and PDGF-AB,are secreted by astrocytoma [18]. There are two types of PDGF receptors: PDGF- $\alpha-R$ and PDGF- $\beta-R$, and the latter is found in meningioma. Astrocytoma has PDGF- $\alpha-\mathrm{R}$ receptor and their growth is stimulated by PDGF in an autocrine fashion. PDGF-BB acting via this receptor increases c-fos level and also meningioma cell division [16]. PDGFB is known to induce oligodendroglia tumors in a mouse model without $1 \mathrm{p} / 19 \mathrm{q}$ loss of heterozygosity (LOH) [19]. Thus, astrocytoma may stimulate growth in adjacent cells by production of common growth factors. Kengo Suzuki et al. [20], immunohistochemically showed that platelet-derived growth factor (PDGF) receptors- $\alpha$ and $\beta$ were overexpressed in glioblastoma multiform meningioma, thereby indicating the oncogenic effects of activated signaling of these receptors. This hypothesis let us speculate that the collision tumor might have been caused by malignant transformation of the reactive gliosis surrounding the meningioma. However, this theory fails to explain why this transformation happened in this particular case and not in the vast majority of intracranial meningioma. This hypothesis also fails to explain the simultaneous occurrence in some cases with the two tumors far apart from each other.
The development and progression of meningioma and glioma is likely to be involved in common genes [21]. Especially in collision tumors, in which the neoplasia grows with mixed tumor matrices, the histological picture suggests a common pathogenetic pathway. There may be a potential common "pathogenetichits" site for astrocytoma and meningioma. Identified as $\mathrm{N}$-myc downstream-regulated gene 2(NDRG2), it was commonly activated in clinically aggressive meningioma [22]. Recently, down-regulation of the NDRG2 gene on $14 \mathrm{q}$ was shown to be associated with a higher WHO grade and a clinically more aggressive course [22]. An earlier research showed that this same gene was expressed in normal brain tissue but down regulated in glioma [23]. Thus, inactivation of NDRG 2 may play a role in the pathogenesis of both meningioma and glioma. Nestler U et al. [24], displayed the result of comparative genomic hybridization (CGH) and chromosome analysis in two patients who presented with glioblastoma simultaneously with meningioma. They believe that, genetic models that could explain the progression of meningioma into glioblastoma do not exist. In their case, they did not find a common genetic aberration in tumor cells with a different histology. Although the two tumor types were adjacent, pathological examinations did not show the invasion between the tumors in all reported cases. Therefore, it is believed that this collision or simultaneous tumor might have formed by chance.

A small handful of case reports describing trauma precedes the occurrence of the glioma at the same brain location. Central nervous system injury initiates reactive gliosis

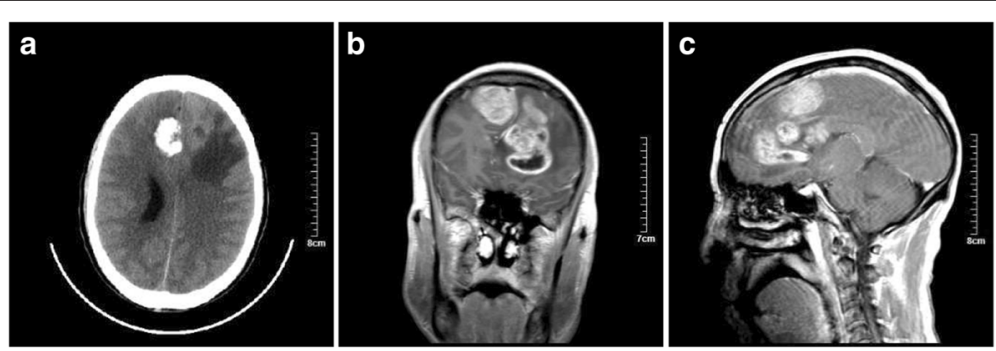

Fig. 4 Computed tomography (CT) and magnetic resonance imaging (MRI) images of patient one. Pre-operative non- contrast computed tomography $(C T)$ scan shows the right frontal falx meningioma with calcification and left frontal mass lesion (axial view) (a). T1-weighted images with gadolinium contrast. Coronary (b) and sagittal (c) views showed the right frontal falx meningioma and the left frontal and corpus callosum high-grade glioma 

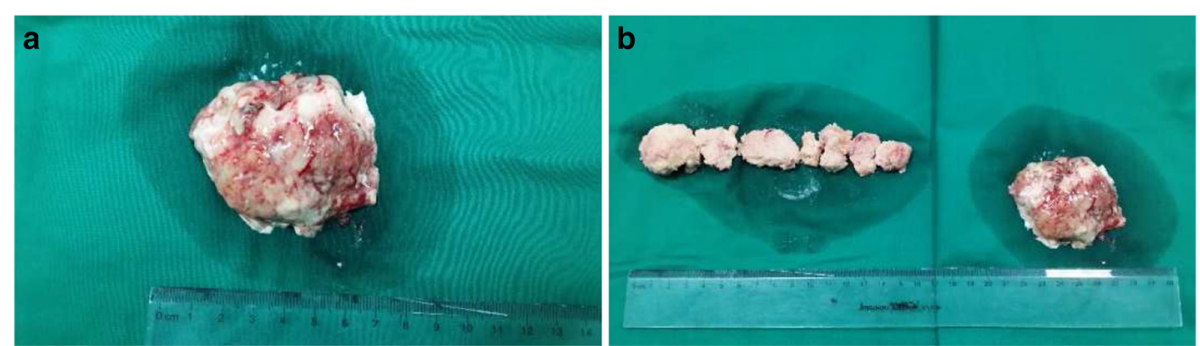

Fig. 5 Surgical specimen of patient two (a and $\mathbf{b})$. The left frontal and corpus callosum surgical specimen (a). The right frontal tumor fragments with the left frontal surgical specimen (b)

and angiogenesis. Fibroblast growth factor-2 is overexpressed in the injured brain. The factor is implicated in both transition of quiescent astrocytes to proliferation and the neoplastic transformation of glioma cells [25, 26]. A few cases of meningioma after trauma have been reported [27]. The occurrence of glioma has been reported after trauma [28]. One of these three case had an obvious history of the observed collision of astrocytoma and meningioma occurred 30 years after the trauma [8]. Therefore, it appears that trauma might play a role in the formation of collision or simultaneous tumors. There were no previous histories of trauma in both patients in our cases.

Careful preoperative radiological evaluation and an apt operation strategy are of great importance in these patients. The problems related to the simultaneous occurrence of meningioma with astrocytoma concern the correct preoperative diagnosis. Low-density areas surrounding meningioma usually represent peritumoral edema and exceptionally a low-grade astrocytoma [29]. An intraoperative biopsy of the brain tissue surrounding a meningioma should be performed in doubtful cases [8]. An enlarging brain hypointensity around a meningioma after removal of meningioma during the follow-up may also suggest a biopsy. Jun P et al. [30], demonstrated how pMRI (dynamic, contrast enhanced, susceptibility-weighted perfusion MR imaging) could identify regions of hemodynamic differences between 2 unique tissue types that were not apparent on conventional anatomic MR imaging. Thus, perfusion MR

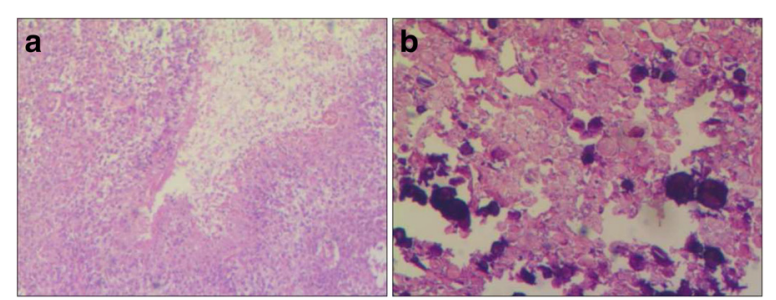

Fig. 6 Hematoxylin and eosin (H\&E) staining showing the results of pathological examinations of patient two (a and $\mathbf{b})$. Psammomatous meningioma WHO I (a) and Anaplastic astrocytoma WHO III (b) (H\&E $\times 400$, medium power) imaging may be helpful to distinguish collision tumors negative on conventional anatomic MR imaging.

The surgical management of meningioma is undoubtedly influenced by the presence of astrocytoma. When the two lesions are contiguous, they usually were removed in a one-stage operation with no or little additional surgical risk [1]. In our first case, we simply followed the standpoint that the lesion causing the main neurological symptoms should be removed first, whether it is a meningioma or an astrocytoma. We also thought that, after removal of meningioma at first stage, we would avoid postoperative brain swelling due to resection of malignant astrocytoma. However, in our first case, after removal of meningioma, intratumoral hemorrhage appeared in the astrocytoma. This patient had no medical co-morbidities such as arterial hypertension, trauma, coagulopathy and intraoperative anesthetic complications. This means that the causal relationship between surgery and this complication can be rated as highly probable. We suggest that the two lesions should be removed at one stage, when they are closely situated. In our second case, we used one-stage removal of two tumors. We did not know whether this surgical management could create significant brain decompression and improve the quality of life in this kind of patients.

When the two tumors are distant from each other, glioma must be removed, because the outcome depends on its evolution. Meningioma is considered symptomatic

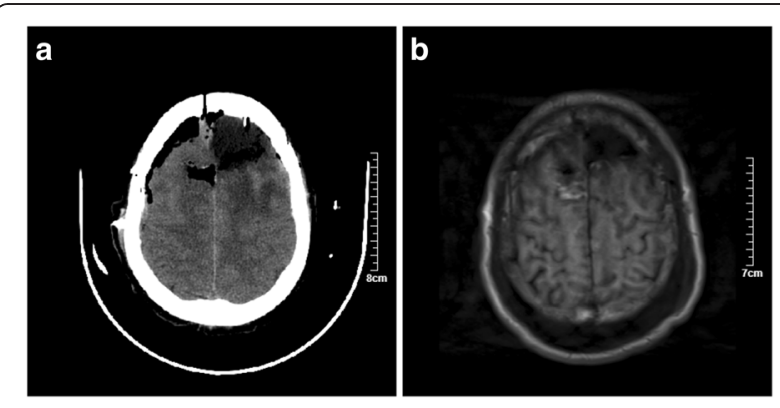

Fig. 7 Post-operative computed tomography (CT) and magnetic resonance imaging (MRI) images patient two. Immediately postoperative $\mathrm{CT}$ (a) and MRI (b) axial views, demonstrate tumor residual cavity 
Table 3 Reported cases of simultaneous or collision astrocytoma and meningioma

\begin{tabular}{|c|c|c|c|c|c|c|c|c|}
\hline N. cases & Author(year) & Age/Sex & $\begin{array}{l}\text { Location of } \\
\text { meningioma }\end{array}$ & $\begin{array}{l}\text { Location of } \\
\text { astrocytoma }\end{array}$ & Clinical presentation & $\begin{array}{l}\text { Radiological } \\
\text { diagnosis }\end{array}$ & Pathological diagnosis & $\begin{array}{l}\text { Treatment (after first } \\
\text { operation. month) }\end{array}$ \\
\hline 1 & $\begin{array}{l}\text { F.Maiuri et al. } \\
\text { [1]. (2005) }\end{array}$ & $68 \mathrm{~F}$ & $\begin{array}{l}\text { Flax (posterior third } \\
\text { left) }\end{array}$ & Right temporal & $\begin{array}{l}\text { Asymptomatic (T.I.A with } \\
\text { ischemia) }\end{array}$ & MRI & Low-grade astrocytoma & $\begin{array}{l}\text { Two-stage } \\
\text { removal (12 mo.) }\end{array}$ \\
\hline 2 & & $65 \mathrm{M}$ & $\begin{array}{l}\text { Flax (anterior } \\
\text { third left) }\end{array}$ & Left-frontal & Generalized epileptic seizure & CT & WHO grade II astrocytoma & $\begin{array}{l}\text { One-stage removal, } \\
\text { irradiation }\end{array}$ \\
\hline 3 & $\begin{array}{l}\text { Goyal et al. } \\
\text { [31] (2003) }\end{array}$ & $34 \mathrm{~F}$ & Tentorial & Right frontal & $\begin{array}{l}\text { Generalized tonic clonic } \\
\text { seizure and headache }\end{array}$ & MRI & $\begin{array}{l}\text { Anaplastic } \\
\text { astrocytomaTransitional } \\
\text { meningioma }\end{array}$ & Two-stage removal (10 day) \\
\hline 4 & $\begin{array}{l}\text { Prayson et al. } \\
\text { [3] (2002) }\end{array}$ & $87 \mathrm{~F}$ & Right frontal lobe & Right frontal lobe & $\begin{array}{l}\text { Progressive left hemiparesis } \\
\text { urinary incontinence }\end{array}$ & MRI & $\begin{array}{l}\text { Malignant astrocytoma } \\
\text { Syncytial meningioma }\end{array}$ & One-stage removal \\
\hline 5 & $\begin{array}{l}\text { Spallone et al. } \\
\text { [7] (1991) }\end{array}$ & $47 \mathrm{M}$ & $\begin{array}{l}\text { Right parieto- } \\
\text { occipital }\end{array}$ & $\begin{array}{l}\text { Right temporo- } \\
\text { parietal }\end{array}$ & $\begin{array}{l}\text { Generalized seizures and } \\
\text { intellectual impairment }\end{array}$ & CT & $\begin{array}{l}\text { Astrocytoma (WHO II) } \\
\text { Psammomatous meningioma }\end{array}$ & $\begin{array}{l}\text { Two-stage removal ( } 15 \text { month) } \\
\text { chemotherapyirradiation }\end{array}$ \\
\hline 6 & & $48 \mathrm{~F}$ & Cavernous sinus & $\begin{array}{l}\text { Left } \\
\text { paraventricular }\end{array}$ & Headache and confusion & CT & $\begin{array}{l}\text { Malignant astrocytoma } \\
\text { Fibroblastic }\end{array}$ & $\begin{array}{l}\text { Stereotactic biopsy-irradiation- } \\
\text { chemotherapy }\end{array}$ \\
\hline 7 & $\begin{array}{l}\text { Dario. A et al. } \\
\text { [9] (1995) }\end{array}$ & $58 \mathrm{~F}$ & Parietal parasagittal & Right temporal & $\begin{array}{l}\text { Progressive mental } \\
\text { deterioration seizures }\end{array}$ & CT & Anaplastic astrocytoma & Two-stage removal (22 mon.) \\
\hline 8 & $\begin{array}{l}\text { Arnetoli. G et al. } \\
\text { [32] (1983) }\end{array}$ & $44 \mathrm{M}$ & Right parasagittal & Right parietal & $\begin{array}{l}\text { Fainting spells of epileptic } \\
\text { nature }\end{array}$ & $\begin{array}{l}\text { CTCarotid } \\
\text { angiography }\end{array}$ & $\begin{array}{l}\text { Protoplasmic astrocytoma } \\
\text { angioblastic meningioma }\end{array}$ & $\begin{array}{l}\text { One-stage removal } \\
\text { Chemotherapy }\end{array}$ \\
\hline 9 & $\begin{array}{l}\text { Khalatbari et al. } \\
\text { [33] (2010) }\end{array}$ & $12 \mathrm{M}$ & $\begin{array}{l}\text { Left ventricular } \\
\text { trigone }\end{array}$ & $\begin{array}{l}\text { Left ventricular } \\
\text { trigone }\end{array}$ & Headache nausea seizures & MRI & $\begin{array}{l}\text { Anaplastic astrocytoma } \\
\text { (WHO grade III) }\end{array}$ & One-stage removal \\
\hline 10 & $\begin{array}{l}\text { Tokunaga, T., et al. } \\
\text { [34] (1991) }\end{array}$ & $69 \mathrm{~F}$ & Right parietal lobe & $\begin{array}{l}\text { Right parietal } \\
\text { convexity }\end{array}$ & Partial seizure of the left arm & $\begin{array}{l}\text { CTCarotid } \\
\text { angiography }\end{array}$ & $\begin{array}{l}\text { Moderately differentiated } \\
\text { astrocytoma }\end{array}$ & One-stage removal irradiation \\
\hline 11 & $\begin{array}{l}\text { Zhang et al. } \\
\text { [35] (2015) }\end{array}$ & $39 \mathrm{M}$ & $\begin{array}{l}\text { Left lateral ventricular } \\
\text { trigone }\end{array}$ & $\begin{array}{l}\text { Left lateral } \\
\text { ventricular trigone }\end{array}$ & Headaches and dizziness & CTMRI & $\begin{array}{l}\text { Oligodendrocytes-astrocytoma } \\
\text { Malignant meningioma }\end{array}$ & $\begin{array}{l}\text { One-stage removal } \\
\text { Gamma-knife radiotherapy }\end{array}$ \\
\hline
\end{tabular}


with a tendency to grow and easily accessible by surgery and large to warrant surgical decompression. A second stage craniotomy for removal of the meningioma may be advisable when the patient is free from progression of glioma. There is a need for conservative management for the patient who is asymptomatic and with a small size or deeply located meningioma and has an established glioblastoma. One may leave the meningioma the place where it occurs, thus decreasing potential morbidity caused by surgical treatment. The short expected life span of patient with glioblastoma also precludes the need to remove the meningioma. Small sized and incidental meningioma was usually followed by periodical MRIs. More over, emphasis should be on a concurrent asymptomatic, calcified, a deep-located meningioma which may require a more radical procedure for resection and place vital structures at risk during treatment.

\section{Conclusion}

In the absence of phacomatosis or prior radiation therapy, the reason for the simultaneous occurrence of astrocytoma with meningioma is not clear, and these tumors could be merely a statistical coincidence. These cases were not associated with phacomatosis and therapeutic radiation. In addition, it would be valuable to study these cases by molecular genetic techniques in the future. Genetic testing of tumor cells in close proximity in the brain will help to answer the questions of possible interactions, common genetic pathways, or familial syndromes in future.

Careful preoperative radiological evaluation and surgical management is of great importance in these patients. One should take special attention to radiological evidence of extraordinary brain edema at a distant site from the meningioma. When these two lesions are closely situated, the best way of surgical intervention is to remove them in a one-stage operation. The management priority for two tumors situated far apart from each other may need case-by-case evaluation.

\section{Consent}

Written informed consent regarding the publication of this case report and its accompanying images was obtained from the patient. Copies of the written consent are available for review upon request.

\footnotetext{
Abbreviations

CGH: Comparative Genomic Hybridization; CNS: Central Nervous System; CT: Computed Tomography; EMA: Epithelial Membrane Antigen; GFAP: Glial Fibrillary Acidic Protein; H\&E: Hematoxylin and Eosin; KPS: Karnofsky Performance Score; LOH: Loss Of Heterozygosity; MRI: Magnetic Resonance Imaging; NDRG2: N-myc Downstream-Regulated Gene 2; PDGFR: Platelet-Derived Growth Factor Receptor; pMRl: dynamic contrast enhanced, susceptibility-weighted perfusion MR imaging; Vim: Vimentin; WHO: World Health Organization.
}

\section{Competing interests}

The authors report no declarations of interest. The authors alone are responsible for the content and writing of the paper.

\section{Authors' contributions}

$\mathrm{AH}$ : Participated in the sequence alignment and drafted the manuscript. QF: Participated in the design of the study. QZ: The operation work. SL: Collected data and carried out the follow-up. XZ: Searched Chinese and English literature. $\mathrm{CL}$ : Participated in the surgical consultation. GDJ: Participated in the surgical consultation. BL: Conceived of the study and participated in the design and coordination and helped to draft the manuscript. All authors read and approved the final manuscript.

\section{Acknowledgment}

Special thanks to Muhemaiti Wahafu and Anaerguli Maimaiti for their help in the preparation of this report.

Received: 19 July 2015 Accepted: 12 November 2015

Published online: 18 March 2016

\section{References}

1. Maiuri $\mathrm{F}$ et al. Simultaneous presentation of meningiomas with other intracranial tumours. Br J Neurosurg. 2005;19(4):368-75.

2. Domenicucci $M$ et al. Meningioma following high-dose radiation therapy. Case report and review of the literature. Clin Neurol Neurosurg. 1990;92(4): 349-52.

3. Prayson RA et al. Collision of a syncytial meningioma and malignant astrocytoma. Ann Diagn Pathol. 2002;6(1):44-8.

4. Deen Jr HG, Laws Jr ER. Multiple primary brain tumors of different cell types. Neurosurgery. 1981;8(1):20-5.

5. Chahlavi A et al. Intracranial collision tumor mimicking an octreotide-SPECT positive and FDG-PET negative meningioma. J Clin Neurosci. 2005;12(6): 720-3.

6. Tally PW, Laws Jr ER, Scheithauer BW. Metastases of central nervous system neoplasms. Case report. J Neurosurg. 1988;68(5):811-6.

7. Spallone A et al. Intracranial meningiomas associated with glial tumours: a review based on 54 selected literature cases from the literature and 3 additional personal cases. Acta Neurochir (Wien). 1991;110(3-4):133-9.

8. Davis GA et al. Concurrent adjacent meningioma and astrocytoma: a report of three cases and review of the literature. Neurosurgery. 1995;36(3):599604. discussion 604-5.

9. Dario A et al. Intracranial meningioma and astrocytoma in the same patient. Case report and review of the literature. J Neurosurg Sci. 1995;39(1):27-35.

10. Matyja E et al. Meningiomas and gliomas in juxtaposition: casual or causal coexistence? Report of two cases. Am J Surg Pathol. 1995;19(1):37-41.

11. Strong AJ et al. Coincidental meningioma and glioma. Report of two cases. J Neurosurg. 1976:45(4):455-8.

12. Melhem ER et al. Diffusion tensor MR imaging of the brain and white matter tractography. AJR Am J Roentgenol. 2002;178(1):3-16.

13. Lee EJ et al. Two primary brain tumors, meningioma and glioblastoma multiforme, in opposite hemispheres of the same patient. J Clin Neurosci. 2002;9(5):589-91.

14. Smith AS et al. Magnetic resonance with marked T2-weighted images: improved demonstration of brain lesions, tumor, and edema. AJR Am J Roentgenol. 1985;145(5):949-55.

15. Vaquero $\mathrm{J}$ et al. Convexity meningioma and glioblastoma in collision. Surg Neurol. 1990;33(2):139-41.

16. Black PM et al. Platelet-derived growth factor expression and stimulation in human meningiomas. J Neurosurg. 1994;81(3):388-93.

17. Yang SY, Xu GM. Expression of PDGF and its receptor as well as their relationship to proliferating activity and apoptosis of meningiomas in human meningiomas. J Clin Neurosci. 2001;8 Suppl 1:49-53.

18. Hermanson $M$ et al. Platelet-derived growth factor and its receptors in human glioma tissue: expression of messenger RNA and protein suggests the presence of autocrine and paracrine loops. Cancer Res. 1992;52(11):3213-9.

19. Dai $C$ et al. PDGF autocrine stimulation dedifferentiates cultured astrocytes and induces oligodendrogliomas and oligoastrocytomas from neural progenitors and astrocytes in vivo. Genes Dev. 2001;15(15):1913-25.

20. Suzuki K et al. Glioblastoma simultaneously present with adjacent meningioma: case report and review of the literature. J Neurooncol. 2010;99(1):147-53. 
21. Iyer VR et al. Three distinct co-existent primary brain tumors in a patient J Cancer Res Ther. 2009;5(4):293-6.

22. Lusis EA et al. Integrative genomic analysis identifies NDRG2 as a candidate tumor suppressor gene frequently inactivated in clinically aggressive meningioma. Cancer Res. 2005;65(16):7121-6.

23. Deng $Y$ et al. N-Myc downstream-regulated gene 2 (NDRG2) inhibits glioblastoma cell proliferation. Int J Cancer. 2003;106(3):342-7.

24. Nestler $\mathrm{U}$ et al. Glioblastoma simultaneously present with meningioma-report of three cases. Zentralbl Neurochir. 2007;68(3):145-50.

25. Joy A et al. Nuclear accumulation of FGF-2 is associated with proliferation of human astrocytes and glioma cells. Oncogene. 1997;14(2):171-83.

26. Pereira EA et al. Rapid development of glioblastoma at the site of atypical meningioma resection. Br J Neurosurg. 2010;24(4):471-3.

27. Preston-Martin S et al. An international case-control study of adult glioma and meningioma: the role of head trauma. Int J Epidemiol. 1998;27(4):579-86,

28. Henry PT, Rajshekhar V. Post-traumatic malignant glioma: case report and review of the literature. Br J Neurosurg. 2000;14(1):64-7.

29. Mikhael MA. Case report: diminished density surrounding a meningioma, verified to be an overlying cystic astrocytoma. J Comput Assist Tomogr. 1977;1(3):349-51.

30. Jun $P$ et al. Perfusion MR imaging of an intracranial collision tumor confirmed by image-guided biopsy. AJNR Am J Neuroradiol. 2006;27(1):94-7.

31. Goyal A et al. Simultaneous occurrence of meningioma and glioma in brain: report of two cases. J Clin Neurosci. 2003;10(2):252-4.

32. Arnetoli $\mathrm{G}$ et al. Simultaneous meningioma and glioma. Difficulties of neuroradiological diagnosis. Report of a case. Ital J Neurol Sci. 1983:4(4):481-3.

33. Khalatbari $\mathrm{M}$ et al. Collision tumor of meningioma and malignant astrocytoma. Pediatr Neurosurg. 2010;46(5):357-61.

34. Tokunaga $T$ et al. Multiple primary brain tumors of different histological types-report of two cases. Neurol Med Chir (Tokyo). 1991;31(3):141-5.

35. Zhang $\mathrm{D}$ et al. An intraventricular meningioma and recurrent astrocytoma collision tumor: a case report and literature review. World I Surg Oncol. 2015;13:37.

\section{Submit your next manuscript to BioMed Central and take full advantage of:}

- Convenient online submission

- Thorough peer review

- No space constraints or color figure charges

- Immediate publication on acceptance

- Inclusion in PubMed, CAS, Scopus and Google Scholar

- Research which is freely available for redistribution

Submit your manuscript at www.biomedcentral.com/submit 